\title{
Increased germination and growth rates of pea and Zucchini seed by FSG plasma
}

\author{
Shohreh Khatami ${ }^{1} \cdot$ Arash Ahmadinia $^{2}$ \\ Received: 11 December 2017 / Accepted: 15 April 2018/Published online: 27 April 2018 \\ (C) The Author(s) 2018
}

\begin{abstract}
Recently, cold atmospheric plasma (CAP) with the unique bio-disinfection features is used in various fields of industry, medicine, and agriculture. The main objectives of this work were to design FSG plasma (a semi-automatic device) and investigate the effect of the cold plasma in the enhancement of the Pea and Zucchini seed germination. Plasma irradiation time was studied to obtain a proper condition for the germination enhancement of seeds. The growth rate was calculated by measuring length of root and stem and dry weight of plants treated by plasma. To investigate drought resistance of plants, all treated and untreated samples were kept in darkness without water for $48 \mathrm{~h}$. From the experimental results, it could be confirmed both drought resistance and germination of seedlings increased after plasma was applied to seeds at $30 \mathrm{~s}$, while seeds treated whiten $60 \mathrm{~s}$ showed a decrease in both germination rate and seedling growth.
\end{abstract}

Keywords FSG (fast seed growth) plasma $\cdot$ Germination rate $\cdot$ Drought resistance

\section{Introduction}

Plant's life begins from the seed. Hence, seed health, growth, and resistance to environmental factors are very important. Considering the daily increase world population, increasing demand for food and reduced water resources, and human has to find a way to increase food with lower cost. In order to deal with mentioned problems, increasing seed quality and increasing their resistance to environmental elements (bacteria, drought) can be useful. Seed germination begins when dormant embryo starts to grow. This phase for most seeds begins with imbibition of water. Usually, imbibition starts with water absorption (phase I), and then, the phase II which is a plateau phase and starts with some changes in the amount of water absorption, and a subsequent increase in water content with radicle growth (phase III). Regulation of water and other environmental factors may be critical for improving seed

Shohreh Khatami

shohreh.khatami@yahoo.com

1 Plasma Physics Research Center, Science and Research Branch, Islamic Azad University, Tehran, Iran

2 Young Researchers and Elite Club, Science and Research Branch, Islamic Azad University, Tehran, Iran germination and successive growth, and this should be considered in developing technologies for efficient germination and growth $[1,2]$. Recently, studies show that cold atmospheric plasma systems could promote seed germination and growth [1, 3-15]. Increment seed germination rate, growth development, and crop yield by plasma treatment have been reported in various crops: spinach [16], wheat [8, 13], soybean [9], and radish [17]. Cold atmospheric plasma systems consist of positively and negatively charged particles (free electrons and ions), and neutral activated species including excited molecules, UV photons, long and short lived free radicals, reactive oxygen species, reactive nitrogen species, and some ozone [18]. Cold atmospheric plasma can penetrate into the capsule of the seeds, and the redox reaction inside plant cells induced by oxygen radicals may affect seed germination and growth.

The main aim of this study was to design and construction of semi-automatic cold plasma device and investigates the effect of air plasma on seed germination, seedling growth, and seedlings resistance against darkness and drought. 


\section{Materials and methods}

\section{Seed material}

Both Pea and Zucchini seeds were purchased from Bazram Company and only ripe intact seeds without visible defects were selected.

\section{FSG plasma device}

Self-designed and self-made FSG plasma is shown in Fig. 1. The system consists of high-voltage AC power supply, a gas flow regulator, and a plasma nozzle (gliding arc) with ability of producing $3 \mathrm{~cm}$ plasma. Air gas was used as the main plasma gas $(5 \mathrm{~L} / \mathrm{min})$. The applied voltage was $15 \mathrm{kV}$, and the distance between the opening of the plasma nozzle and the samples was $1 \mathrm{~cm}$ for all cases of plasma treatment.

The mechanical part consists of a mechatronic arm with two degrees of freedom, which has three hinges that work with separate engine. The system controls by real time, and users can choose the device performance. The mechatronic performance of devices in such a way that, at first, the type of commands gives to device by communication panel, and then, they analyze by the main processor and then sent to the movement angle motor and the speed is determined by the Jacobian, and finally, the arm transfers the seed box, the location of the plasma. After treating with plasma, the arm returns the seeds to first chamber.

\section{Microbial analysis}

To investigate the effect of plasma exposure on microorganisms, some seeds from both the untreated and treated sample were selected randomly, and then mixed with $100 \mathrm{~mL}$ of sterile peptone $(0.1 \%)$ and were placed on the shaker for $6 \mathrm{~h}$. After that, $50 \mu \mathrm{L}$ of each sample were spread onto Müller-Hilton agar media and incubated at $35{ }^{\circ} \mathrm{C}$ for overnight. In this study, five replicated samples were used from each treated and untreated sample. The survival curve of microorganism was expressed corresponding to the surface area $\left(\mathrm{CFU} / \mathrm{mL} / \mathrm{cm}^{2}\right)$ of the seeds.

\section{Seed preparation and plasma treatment}

Thirty seeds were kept in sterile deionized water for $1 \mathrm{~h}$. Then, five seeds were placed in the $60 \mathrm{~mm}$ petri dish which was covered by dried filter and exposed to the plasma. Plasma treatment was given at the intervals of 30 and $60 \mathrm{~s}$. Gas treatment without plasma discharge was used as a control. After each treatment, treated seeds immediately were planted in pots with the same measure of the soil (40 $\mathrm{g}$ in each pot) and incubated in growth chamber $\left(25{ }^{\circ} \mathrm{C}, 50 \%\right.$ humidity, light for $16 \mathrm{~h}$, and dark for $8 \mathrm{~h}$ ) for 14 days. Each experiment included six replicates with five seeds per treatment. Seed germination was measured every $24 \mathrm{~h}$ by registering the emergence of the radicle and continued until no more seed germinated. Finally, all treated and untreated seeds were kept in darkness and drought for $48 \mathrm{~h}$ to investigate the resistance of plants against darkness and drought. The mean germination time (MGT) was calculated by Eq. 1 [19]:

$\operatorname{MGT}=\frac{\sum t n}{\Sigma t}$,

where $n$ is the number of germinated seeds after $t$ days, counted from the beginning of germination.
Fig. 1 FSG plasma device: a plasma nozzle, $\mathbf{b}$ schematic of device, and $\mathbf{c}$ the image taken from main device

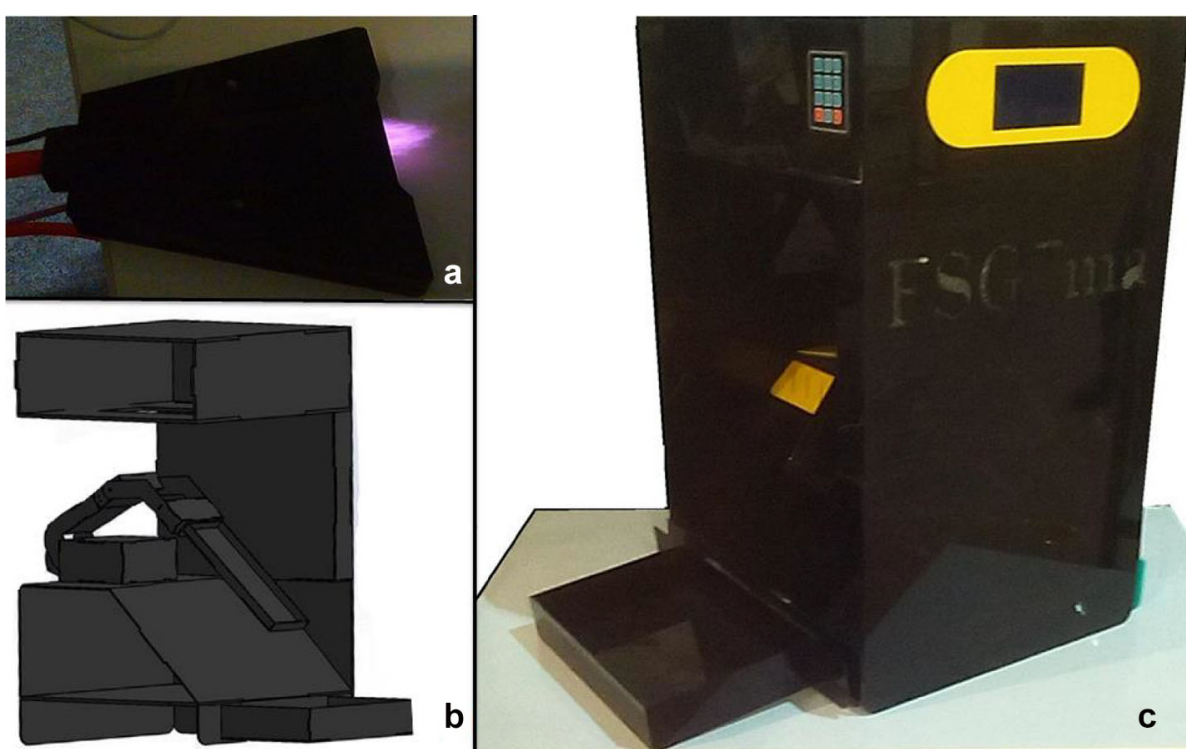


Equation 2 was used to determine the speed of germination $\left(V_{\mathrm{g}}\right)$, where $n_{t}$ is the number of newly germinated seeds at time $t$, counted from the first day [20]:

$V_{\mathrm{g}}=\sum\left(\frac{n_{t}}{t}\right)$.

Ten seeds from both untreated and treated samples randomly selected and the root and shoot of them were measured after 7 days. Then, the selected seeds were dried at $90{ }^{\circ} \mathrm{C}$; dry weight was measured.

\section{Statistical analysis}

The experimental data were expressed as the style of mean value \pm standard deviation (SD). The differences among means were tested for statistical significance by one-way analysis of variance and independent sample $T$ test. The $p$ value $<0.05$ was defined as statistically significant.

\section{Result}

\section{Plasma effect on the microorganisms}

The antibacterial effect of plasma depicts in Fig. 2. The amount of microorganisms on both untreated Pea and Zucchini seeds was $5.5 \pm 0.03\left(\mathrm{CFU} / \mathrm{mL} / \mathrm{cm}^{2}\right)$ and treated with plasma for 30 and $60 \mathrm{~s}$. According to the survival curve, the amount of microorganisms reduced significantly with increasing the plasma treatment times. Cold plasma contains various particles including, positively and negatively charged particles (free electrons and ions), some neutral activated species such as excited molecules, UV

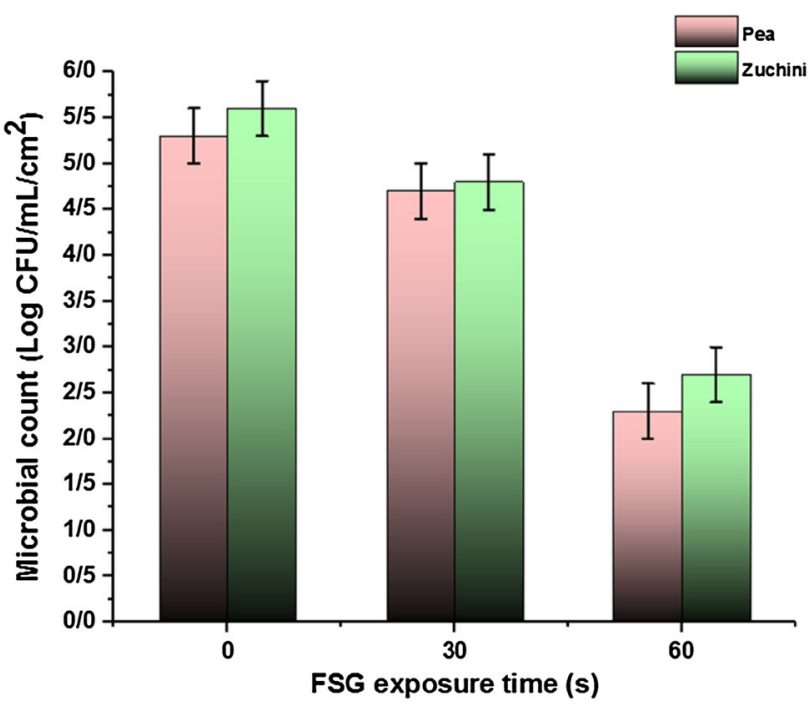

Fig. 2 Survival curve of the surface microorganisms on Pea and Zucchini due to FSG plasma exposure. Seed treatment indicates significant differences at $P<0.05$ level among all treatments photons, long and short lived free radicals, reactive oxygen species (ROS) such as $\mathrm{O}, \mathrm{O}_{2}, \mathrm{O}_{3}$, and $\mathrm{OH}$, reactive nitrogen species (RNS) such as $\mathrm{NO}, \mathrm{NO}_{2}, \mathrm{NO}_{x}$, and ozone that can be used for disinfection of non-living surfaces (medical tools), living tissues, bio-decontamination, and sterilization of heat sensitive material [18]. Many studies have generated different types of cold atmospheric plasma (CAP) and tested their antibacterial activity [21]. It seems that the disinfection efficiency of CAP is related to the specific properties of the devices used and the type of bacteria. Studies have shown cold plasma is being able to effect on different targets within the cell including cell wall intracellular proteins and DNA [18]. Mechanical stress induced by charged species is able to break important bonds in the cell structure [22]. Therefore, this disruption of the outer shell of the cell will lead to leakage of cellular components such as proteins and potassium nucleic acid. After disruption of cell wall structure, reactive species can penetrate into the interior of the cell and further damage DNA and intracellular protein from oxidative and nitrosative species [18]. It should be mentioned here that both unsaturated fatty acids in the membrane lipids and protein molecules imbedded in the lipid bilayer can be susceptible to attacks by these reactive species [21].

\section{Seed germination characteristics}

The effect of FSG with different exposure times on the Pea seeds germination potential is given in Table 1. Pea seeds were treated by cold plasma germinated in the first day. After $10 \mathrm{~h}$, the treated Pea seeds with 30 s plasma exposure germinated, while the seeds which were treated at $60 \mathrm{~s}$ plasma exposure germinated after $15 \mathrm{~h}$ and untreated Pea seeds germinated after $24 \mathrm{~h}$. A significant difference achieved between untreated and treated samples.

The highest percentage of germination is related to the $30 \mathrm{~s}$ plasma exposure $(80.4 \%)$. For samples which were irradiated by plasma foe $30 \mathrm{~s}$, the speed of germination $\left(V_{\mathrm{g}}\right)$, the length of shoot and root, the germination rate, and the seedling dry weigh increased (Table 1).

Germination of Pea seeds was more rapidly increased after treatment with $30 \mathrm{~s}$ high-voltage plasma. After 14 days, about 80 and $74 \%$ of seeds were germinated at 30 and $60 \mathrm{~s}$ treatment, while just $40 \%$ of untreated seeds were germinated. After 14 days, the length of seedlings which were treated by plasma at $30 \mathrm{~s}$ was more than other samples. Figure 3 shows the image of Pea seeds after 7 and 14 days (Fig. 3b, c). As is clearly in images, the maximum growth of shoot and root related to the seeds was treated at $30 \mathrm{~s}$ by plasma exposure.

Table 2 shows the results obtained from Zucchini seeds. The same results with Pea seed were achieved. The most amount of seed germination and growth rate is related to 
Table 1 Germination specifications of obtained from Pea seeds at different FSG plasma exposure times

\begin{tabular}{llllll}
\hline Parameter treatment time (s) & GEM (\%) & MGT (day) & Vg (seed/day) & Seedling length (cm) & Seedling dry weight (mg) \\
\hline Control & 40 & 2.8 & $3.4 \pm 0.1$ & $12.5 \pm 0.3$ & $23 \pm 1$ \\
30 & 80.4 & 3.5 & $7.2 \pm 0.1$ & $23.3 \pm 0.3$ & $52 \pm 3$ \\
60 & 64.6 & 2.7 & $5.3 \pm 0.1$ & $19.2 \pm 0.3$ & $29 \pm 2$ \\
\hline
\end{tabular}

Fig. 3 Image of pea seeds: a workplace, $\mathbf{b}$ after 7 days, and c after 14 days

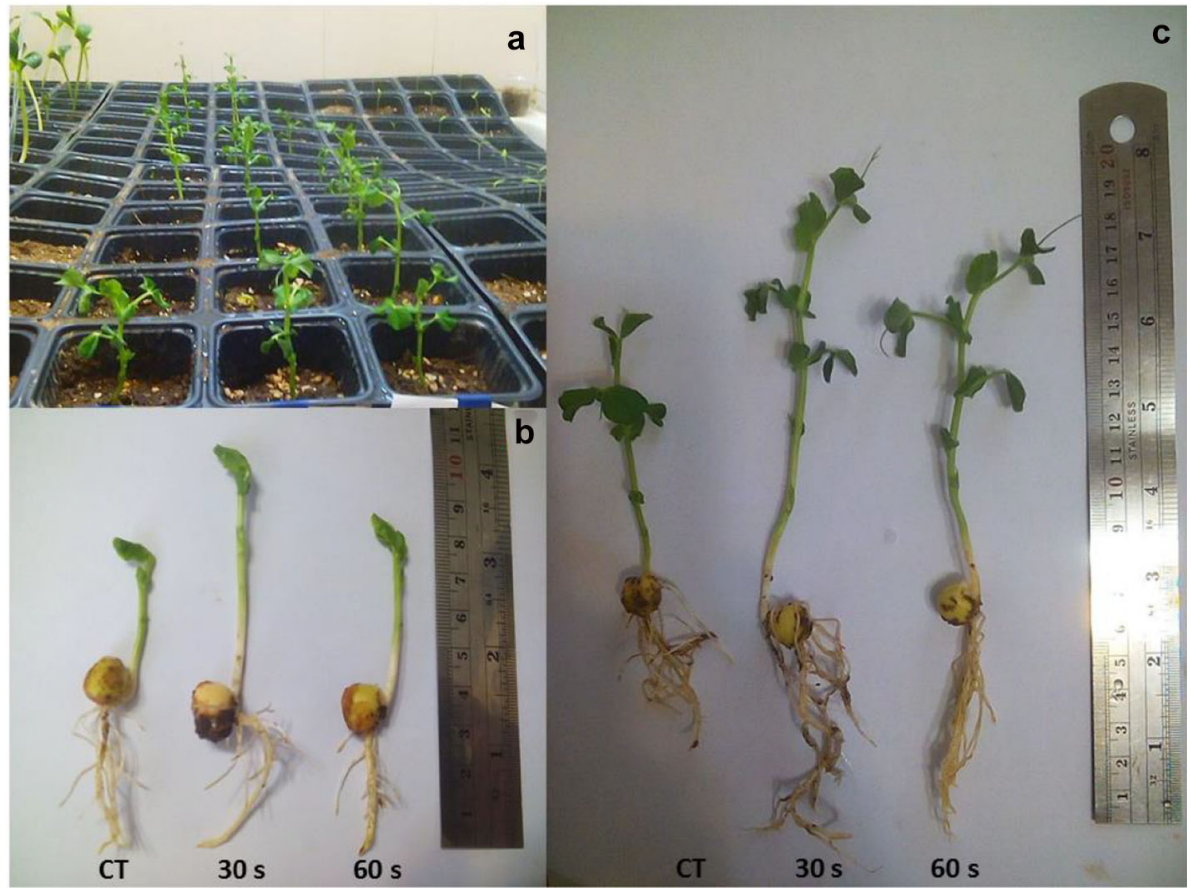

Table 2 Germination specifications obtained from Zucchini seeds at different FSG plasma exposure times

\begin{tabular}{llllll}
\hline Parameter treatment time (s) & GEM (\%) & MGT (day) & Vg (seed/day) & Seedling length (cm) & Seedling dry weight (mg) \\
\hline Control & 38 & 2.8 & $3.6 \pm 0.1$ & $18.1 \pm 0.3$ & $32 \pm 2$ \\
30 & 72.5 & 4.2 & $8.3 \pm 0.1$ & $27.3 \pm 0.3$ & $67 \pm 1$ \\
60 & 50 & 2.8 & $4.5 \pm 0.1$ & $24.4 \pm 0.3$ & $59 \pm 1$ \\
\hline
\end{tabular}

the seed which were treated at $30 \mathrm{~s}$ plasma exposure. However, the total results were less than Pea seeds, so that just $72.5 \%$ and $50 \%$ of Zucchini seeds germinated after treatment at 30 and $60 \mathrm{~s}$ plasma exposure, respectively, while, similarly about $40 \%$ of untreated seeds germinated. The treated Zucchini seeds at $30 \mathrm{~s}$ germinated after $48 \mathrm{~h}$ of plasma exposure, while the untreated Zucchini seeds germinated after 5 days. In contrast, the MGT of Zucchini seeds were more than pea seeds (Table 2).

The images of zucchini seeds are shown in Fig. 4. After 7 days, just the root of untreated Zucchini seeds grew, while the whole length of treated seeds at $30 \mathrm{~s}$ plasma exposure was about $16 \mathrm{~cm}$ (Fig. 4b).
According to the results, some physiological effect decreased after $60 \mathrm{~s}$ of plasma exposure in both seeds. Several factors can be effective. According to the previous reports, some reactive species such as reactive oxygen and nitrogen play a crucial role in the adjustment of abscisic acid (ABA) catabolism and gibberellin (GA) biosynthesis during seed imbibition [23]. GA plays an important role in seed stem elongation, leaf expansion, germination, and seed development processes, while ABA has a significant effect in some physiological processes such as seed maturation, growth, and adaptive responses to environmental stresses, and dormancy [24]. 
Fig. 4 Image of Zucchini seeds, a workplace, $\mathbf{b}$ after 7 days, and c after 14 days

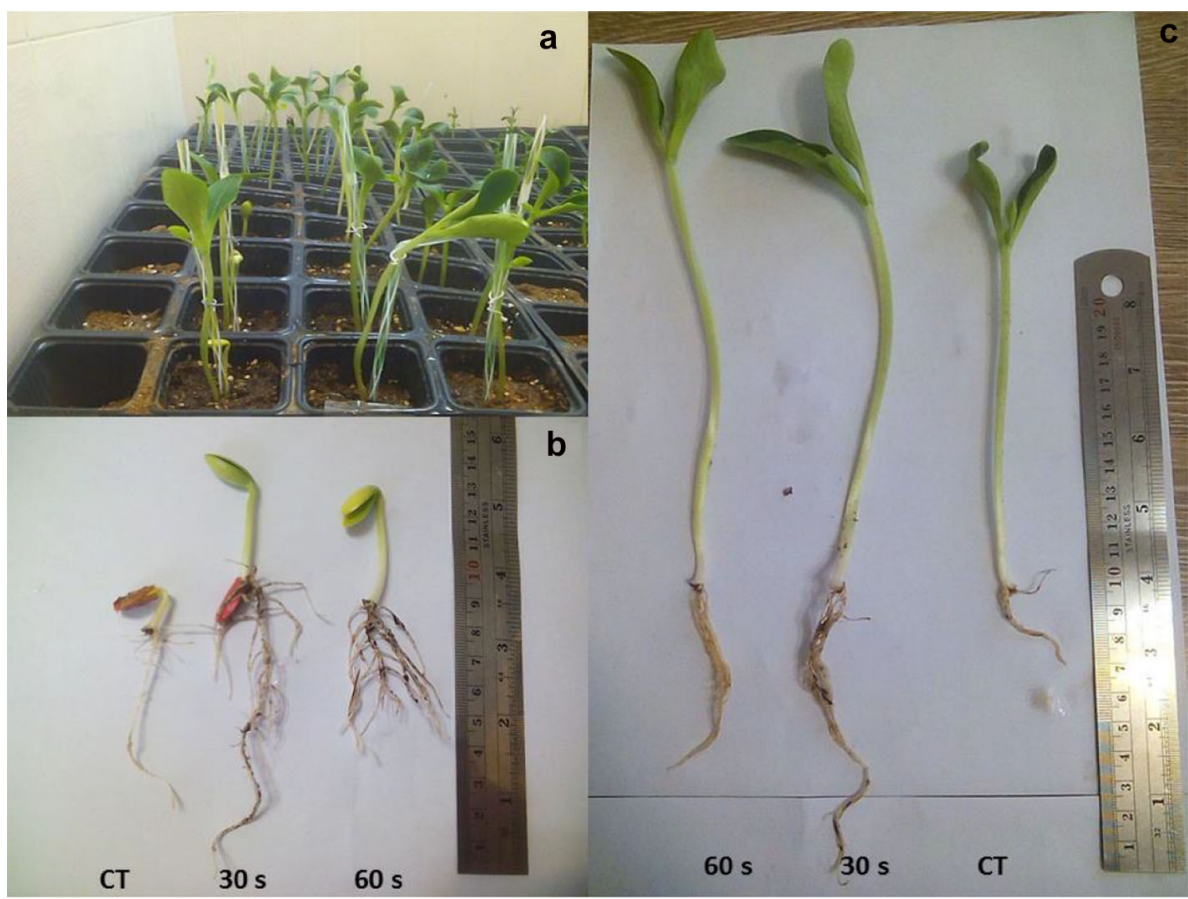

\section{The growth rate under stress condition}

Keeping plants under water and light stress conditions showed that seedlings from untreated seeds withered severely after $48 \mathrm{~h}$, while the seedlings grown from treated seeds had more resistance to the stress. The treated seeds at $30 \mathrm{~s}$ plasma, under water and light stress condition after $48 \mathrm{~h}$ had more resistance than treated samples at $60 \mathrm{~s}$ plasma exposure. In the other experiment, similarly, Ling et al. [25] reported that seed treatment by cold plasma enhanced the germination rate even in drought stress conditions by increasing the absorptive ability attributed to seed imbibition.

\section{Conclusion}

In this study, we made self-design and self-made FSG plasma. The effect of plasma exposure on germination and growth rate and microorganism on seeds surface was investigated. A significant reduction of the seed borne microbial contamination was observed by increasing plasma exposure time. Moreover, increased seed germination was achieved with treatment times at $30 \mathrm{~s}$ for both Pea and Zucchini seeds. It is clear that plasma can increase the speed of plant growth. Hence, we can conclude that the FSG plasma has ability to increase the seed germination and plant resistance against drought and darkness.

Open Access This article is distributed under the terms of the Creative Commons Attribution 4.0 International License (http:// creativecommons.org/licenses/by/4.0/), which permits unrestricted use, distribution, and reproduction in any medium, provided you give appropriate credit to the original author(s) and the source, provide a link to the Creative Commons license, and indicate if changes were made.

\section{References}

1. Meiqiang, Y., Mingjing, H., Buzhou, M., Tengcai, M.: Stimulating effects of seed treatment by magnetized plasma on tomato growth and yield. Plasma Sci. Technol. 7(6), 3143 (2005)

2. Ponce, G., Corkidi, G., Eapen, D., Lledias, F., Cárdenas, L., Cassab, G.: Root hydrotropism and thigmotropism in Arabidopsis thaliana are differentially controlled by redox status. Plant Signal. Behav. 12(4), e1305536 (2017)

3. Considine, M.J., Foyer, C.H.: Redox regulation of plant development. Antioxid. Redox Signal. 21(9), 1305-1326 (2014)

4. Dhayal, M., Lee, S.-Y., Park, S.-U.: Using low-pressure plasma for Carthamus tinctorium L. seed surface modification. Vacuum 80(5), 499-506 (2006)

5. Huang, Y., Zhou, Z.: Applied effect of atmospheric pressure plasma technology to eggplant. Seed 29, 73-75 (2010)

6. Kitazaki, S., Koga, K., Shiratani, M., Hayashi, N.: Growth control of dry yeast using scalable atmospheric-pressure dielectric barrier discharge plasma irradiation. Jpn. J. Appl. Phys. 51(11S), 11PJ02 (2012)

7. Laroussi, M., Akan, T.: Arc-free atmospheric pressure cold plasma jets: a review. Plasma Processes Polym 4(9), 777-788 (2007)

8. Li, Y., Wang, T., Meng, Y., Qu, G., Sun, Q., Liang, D., Hu, S.: Air atmospheric dielectric barrier discharge plasma induced germination and growth enhancement of wheat seed. Plasma Chem. Plasma Process. 37(6), 1621-1634 (2017)

9. Ling, L., Jiafeng, J., Jiangang, L., Minchong, S., Xin, H., Hanliang, S., Yuanhua, D.: Effects of cold plasma treatment on seed germination and seedling growth of soybean. Sci. Rep. 4 (2014). https://doi.org/10.1038/srep05859 
10. Ono, R., Hayashi, N.: Variation of antioxidative activity and growth enhancement of Brassicaceae induced by low-pressure oxygen plasma. Jpn. J. Appl. Phys. 54(6S2), 06GD03 (2015)

11. Park, D.P., Davis, K., Gilani, S., Alonzo, C.-A., Dobrynin, D., Friedman, G., Fridman, A., Rabinovich, A., Fridman, G.: Reactive nitrogen species produced in water by non-equilibrium plasma increase plant growth rate and nutritional yield. Curr. Appl. Phys. 13, S19-S29 (2013)

12. Šerá, B., Gajdová, I., Šerý, M., Špatenka, P.: New physicochemical treatment method of poppy seeds for agriculture and food industries. Plasma Sci. Technol. 15(9), 935 (2013)

13. Sera, B., Spatenka, P., Sery, M., Vrchotova, N., Hruskova, I.: Influence of plasma treatment on wheat and oat germination and early growth. IEEE Trans. Plasma Sci. 38(10), 2963-2968 (2010)

14. Zhou, Z., Huang, Y., Deng, M., Yang, S.: Effects of eggplant seed treatment with atmospheric pressure plasma on plant growth and yield. China Veg. 4, 62-66 (2010)

15. Zhou, Z., Huang, Y., Yang, S., Chen, W.: Introduction of a new atmospheric pressure plasma device and application on tomato seeds. Agric. Sci. 2(1), 23-27 (2011)

16. Ji, S.-H., Choi, K.-H., Pengkit, A., Im, J.S., Kim, J.S., Kim, Y.H., Park, Y., Hong, E.J., Kyung Jung, S., Choi, E.-H.: Effects of high voltage nanosecond pulsed plasma and micro DBD plasma on seed germination, growth development and physiological activities in spinach. Arch. Biochem. Biophys. 605, 117-128 (2016)

17. Matra, K.: Non-thermal plasma for germination enhancement of radish seeds. Procedia Comput. Sci. 86, 132-135 (2016)

18. Mai-Prochnow, A., Murphy, A.B., McLean, K.M., Kong, M.G., Ostrikov, K.K.: Atmospheric pressure plasmas: infection control and bacterial responses. Int. J. Antimicrob. Agents 43(6), 508-517 (2014)
19. Sadeghi, H., Khazaei, F., Yari, L., Sheidaei, S.: Effect of seed osmopriming on seed germination behavior and vigor of soybean (Glycine max L.). ARPN J. Agric. Biol. Sci. 6(1), 39-43 (2011)

20. Maguire, J.D.: Speed of germination-aid in selection and evaluation for seedling emergence and vigor. Crop Sci. 2(2), 176-177 (1962)

21. Laroussi, M., Leipold, F.: Evaluation of the roles of reactive species, heat, and UV radiation in the inactivation of bacterial cells by air plasmas at atmospheric pressure. Int. J. Mass Spectrom. 233(1), 81-86 (2004)

22. Laroussi, M., Mendis, D., Rosenberg, M.: Plasma interaction with microbes. New J. Phys. 5(1), 41 (2003)

23. Rajjou, L., Duval, M., Gallardo, K., Catusse, J., Bally, J., Job, C., Job, D.: Seed germination and vigor. Annu. Rev. Plant Biol. 63, 507-533 (2012)

24. Liu, Y., Ye, N., Liu, R., Chen, M., Zhang, J.: $\mathrm{H}_{2} \mathrm{O}_{2}$ mediates the regulation of ABA catabolism and GA biosynthesis in Arabidopsis seed dormancy and germination. J. Exp. Bot. 61(11), 2979-2990 (2010)

25. Ling, L., Jiangang, L., Minchong, S., Chunlei, Z., Yuanhua, D.: Cold plasma treatment enhances oilseed rape seed germination under drought stress. Sci. Rep. 5 (2015). https://doi.org/10.1038/ srep13033

\section{Publisher's Note}

Springer Nature remains neutral with regard to jurisdictional claims in published maps and institutional affiliations. 